\title{
Development of a Matlab Code for Plane Wave Lens and its Validation by Autodyn-2D
}

\author{
Khalid Naeem \\ School of Chemical and Materials Engineering \\ National University of Sciences and Technology \\ Islamabad, Pakistan \\ khalid.phd@scme.nust.edu.pk
}

\author{
Arshad Hussain \\ School of Chemical and Materials Engineering \\ National University of Sciences and Technology \\ Islamabad, Pakistan \\ principal@scme.nust.edu.pk
}

\begin{abstract}
Plane wave generator is normally composed of two explosives having dissimilar detonation velocity. It is used for directing the spherically outgoing shock wave front to a planar form. Plane wave generators are utilized to find material behavior under dynamic loading. This paper presents the shock arrival time for two plane wave generators by developed Matlab code and its comparison with Ansys Autodyn. The diameter of both plane wave generators is kept the same. One plane wave generator is composed of Octogen and Barium Nitrate and the other is composed of Octogen and Tri Nitro Toluene. Obtained results were surprisingly in agreement. Maximum and minimum obtained flatness for the plane wave were \pm 0.56 and $\pm 0.08 \mathrm{~ms}$ respectively within the whole diameter of the plane wave generator. The developed code can be utilized to find the profile of a plane wave generator, minimizing the time and cost many times.
\end{abstract}

Keywords-plane wave lens; HMX; TNT; Matlab; shock front; explosive lens

\section{INTRODUCTION}

In order to investigate materials at higher pressures, it is necessary to accelerate materials under consideration to higher velocities. The techniques or instruments required to achieve higher velocities are: gas gun, electromagnetic rail gun, Van de Graaf accelerator, plasma accelerators, electric gun or electric discharge technique, and plane wave generator. Gas gun is a device which uses light gas to propel the specimen. Before operation of the gun, a light gas is compressed, the compressed gas is then fed at once to the launching tube where the sample is accelerated. Gas gun consists of a single or double stage. A pressure up to $100 \mathrm{GPa}$ can be achieved by a two stage gas gun [1]. Electromagnetic rail gun can accelerate few grams to 7$7.5 \mathrm{~km} / \mathrm{s}$ [2]. Van de Graaf accelerators are used to accelerate atomic particles up to $100 \mathrm{~km} / \mathrm{s}$ [3]. A velocity up to $18 \mathrm{~km} / \mathrm{s}$ can be achieved with plasma accelerators and electrical discharge [4]. Use of explosives is another means of attaining high impact velocity. It is utilized for material acceleration in two different ways. In the first method the explosive detonation front is directly used for accelerating the sample material and in the second method the detonation wave front is used to compress a light gas which is further utilized to launch the projectile [5].
Plane wave generator (PWG) is also used to study hypervelocity impact. It is an explosive lens made up of two explosives [6]. PWG maneuvers the spherically outgoing detonation wave front to planar form. The planar detonation wave front can be achieved either by combining two explosives having dissimilar velocity of detonation (VOD) or a single explosive having some inert barrier inside [6]. PWG is manufactured by machining. In this process both dissimilar explosives are first machined and then assembled in a costly process. It can be produced by pressing to shape with dies [7]. PWG designed from nitromethane and lead has been reported in [8]. Due to its toxic nature, lead is difficult to handle. Therefore a low equivalent liquid explosive lens without lead was presented in [9]. An explosive lens composed of two explosives gives better results than a single explosive having some inert material [10]. PWG is utilized to accelerate objects to hyper velocities in order to study their various parameters and to find the equation of state for gases [11]. It is also utilized for overdriving high explosives to get maximum jet velocity in case of shaped charges [12]. Massive hypervelocity pellet can be obtained by firing the shaped charge. The liner is fabricated from the material to be tested. Once fired the tip of shaped charge jet moving at a speed of 7.57 to $10.95 \mathrm{~mm} / \mu$ s is isolated from the rest of the jet and slug [13]. PWGs are also used for shock hardening of materials. The specimen is shock hardened when a flyer plate accelerated by PWG hit the specimen encased within heavy metal casing [14].

\section{MATERIALS AND METHODS}

\section{A. Mathematical Model for $P W G$}

The assumptions made for the development of the mathematical model are:

- The detonation is mature and a steady state VOD is achieved at the start of detonation without any run distance.

- The velocity of the detonation is uniform throughout the explosive regardless of its diameter.

- Low VOD explosive is detonated without any misbehavior.

The parameters shown in Figure 1 are required for designing a $\mathrm{PWG}$ (height of $\mathrm{PWG}=\mathrm{h}$, diameter of $\mathrm{PWG}=\mathrm{d}$, VOD of explosive- $1=\mathrm{V}_{1}$ and VOD of explosive $-2=\mathrm{V}_{2}$ ). 


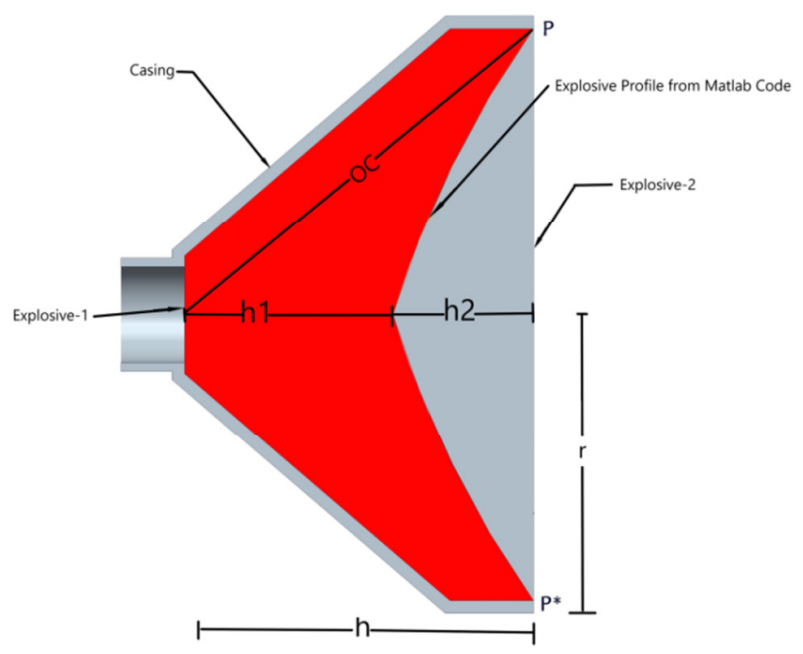

Fig. 1. Cross sectional view of a PWG

PWG is designed in a way to get a plane detonation wave front at $\mathrm{PP}^{*}$ given in Figure 1. With the help of Figure 1 this condition is written mathematically:

$$
\begin{aligned}
& \mathrm{T}_{\mathrm{PWG}}=\frac{\mathrm{OC}}{\mathrm{V}_{1}} \\
& \mathrm{OC}=\sqrt{\mathrm{h}^{2}+\mathrm{r}^{2}} \\
& \mathrm{~T}_{\mathrm{PWG}}=\mathrm{T}_{1}+\mathrm{T}_{2}
\end{aligned}
$$

where:

$$
\mathrm{T}_{1}=\frac{\mathrm{h}_{1}}{\mathrm{v}_{1}} \text { and } \mathrm{T}_{2}=\frac{\mathrm{h}_{2}}{\mathrm{v}_{2}}
$$

Therefore (1), (3) and (4) can be written in the form of (5):

$$
\frac{\mathrm{OC}}{\mathrm{V}_{1}}=\frac{\mathrm{h}_{1}}{\mathrm{~V}_{1}}+\frac{\mathrm{h}_{2}}{\mathrm{~V}_{2}}
$$

A small step size in the y direction is taken for granted (let $\Delta y=0.25)$ and the corresponding value for $x$ coordinate is calculated using (4). The values of $h_{1}$ and $h_{2}$ are given by (6):

$$
h_{1}=\sqrt{x_{1}^{2}+\Delta y^{2}} \text { and } h_{2}=\sqrt{x_{2}^{2}-x_{1}^{2}}
$$

Finally the boundary conditions are applied and the code is run in a loop. By decreasing the step size $\Delta y$, the number of points increases. For the Octogen (HMX) and Barium Nitrate (Baratol) PWG height, diameter, velocities of detonation for HMX and Baratol were taken as 50.0, 45.0, 8.73 and 4.90 respectively. Matlab was selected for code writing as it contains built in functions for plotting. The flowchart given in Figure 2 was followed during the writing of the code.

\section{B. Methodology}

Following the flow chart given in Figure 2, code was written to obtain the profile of PWG at four decreasing step sizes of $0.5,0.25,0.125$ and $0.0625 \mathrm{~mm}$. By reducing the step size in Matlab by 50, 75 and 87.5 percent i.e. from 0.5 to 0.25 , 0.125 and 0.0625 the percent increase in the number of steps was 97.4, 294.9 and 689.7 for the HMX-Baratol PWG and 99, 298 and 696 for HMX TNT PWG respectively.

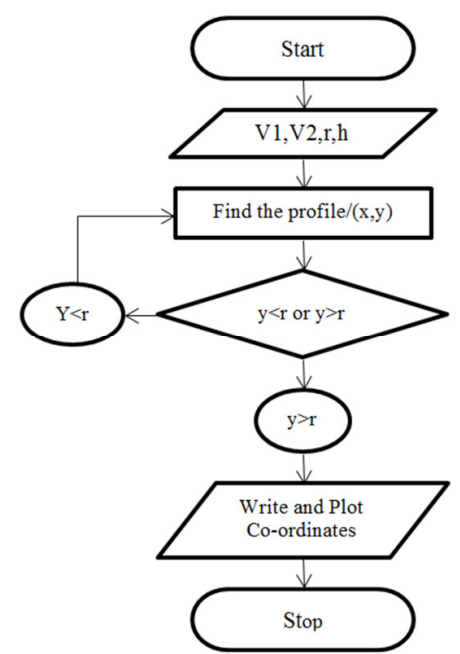

Fig. 2. Flow chart of the code
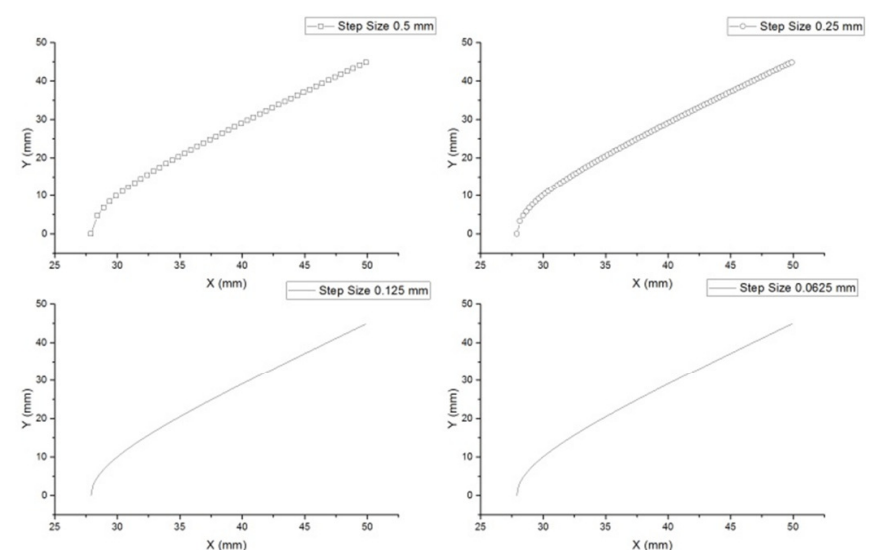

Fig. 3. PWG profile of HMX and Baratol at decreasing step size
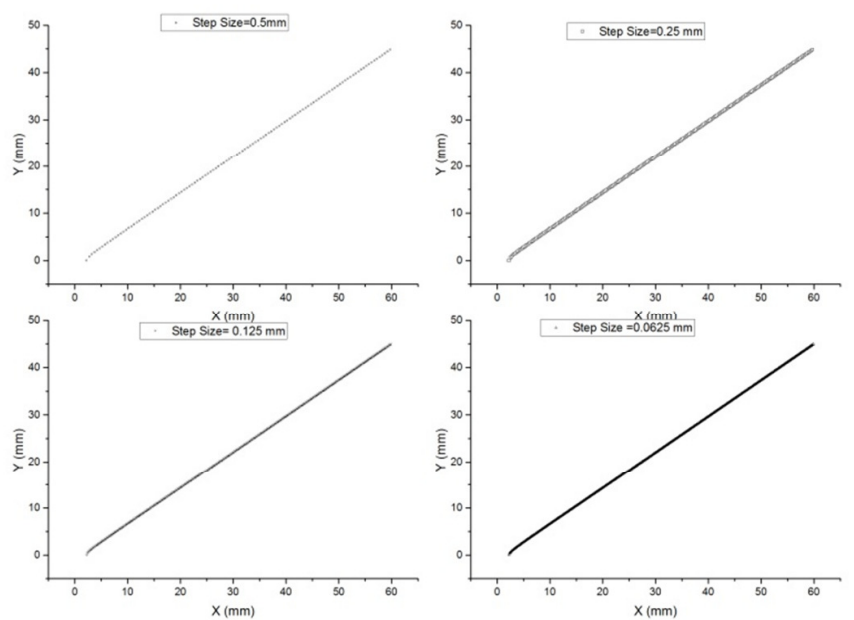

Fig. 4. PWG profile of HMX and TNT at decreasing step size

\section{Simulations}

The obtained profiles from Matlab were plotted in Cadkey. Two arcs were fit to the entire points for simplicity, each arc 
was drawn by selecting three points on the profile so as a whole only six points were taken from the whole profile points. This practice was performed in order to model easily the PWG profile in Ansys Autodyn. Simulations were run in two dimensional axial symmetry in order to save time and computer resources [15]. Mesh density greatly affects the simulation results: increasing the mesh density increases the time required for simulation including accuracy and vice versa [16]. The employed mesh in all simulations had a cell size of $0.33 \mathrm{mmx} 0.33 \mathrm{~mm}$ per cell for the entire domain. The boundary condition for the problem was set to flow out, which mimics the condition that materials once moved out of the boundary do not participate in any sort of action. Jones-Wilkens-Lee (JWL) equation-of-state was used to model HMX, TNT and Baratol. General form of the JWL equation for the solid unreacted and gases reacted phase is given by (7) [17]:

$$
P=A\left[1-\frac{\omega}{R_{1} V}\right] e^{-R_{1} V}+B\left[1-\frac{\omega}{R_{2} V}\right] e^{-R_{2} V}+\frac{\omega E}{V}
$$

where $P, V$ and $E$ in the equation represent detonation pressure, relative volume and internal energy per unit volume of the explosive respectively, whereas $A, B, \omega, R_{1}$ and $R_{2}$ are all constants. The JWL parameters for all the three explosives are given in Table I.

TABLE I. JWL EQUATION OF STATE FOR HMX, BARATOL AND TNT

\begin{tabular}{|c|c|c|c|}
\hline & HMX [18] & Baratol [19] & TNT [18] \\
\hline Density (kg/mm $\mathbf{3})$ & 1740 & 2600 & 1630 \\
\hline $\mathbf{V ~ ( m / s ) ~}$ & 8730 & 4900 & 6930 \\
\hline $\mathbf{P}(\mathbf{G P a})$ & 31.1 & 11.0 & 21.0 \\
\hline $\mathbf{A}(\mathbf{G P a})$ & 748 & 1265 & 373.7 \\
\hline $\mathbf{B}(\mathbf{G P a})$ & 12.1 & 1.55 & 374.7 \\
\hline $\mathbf{R}_{\mathbf{1}}$ & 4.5 & 5.8 & 4.15 \\
\hline $\mathbf{R}_{\mathbf{2}}$ & 1.1 & 2.0 & 0.9 \\
\hline $\mathbf{\omega}$ & 0.3 & 0.6 & 0.35 \\
\hline $\mathbf{E}\left(\mathbf{j} / \mathbf{m m}^{\mathbf{3}}\right) \mathbf{m}$ & 10.2 & 11 & 6.0 \\
\hline
\end{tabular}

To study the effects of boat tailing and casing the following four cases were studied.

\section{1) Without Boat Tailing}

- Without casing

- With $2 \mathrm{~mm}$ aluminum casing

2) With Boat Tailing

- Without casing

- With $2 \mathrm{~mm}$ aluminum casing

\section{Simulation Results}

Shock front arrival times, obtained from Autodyn for the HMX- Baratol PWG without and with boat tailing and for each of the two cases, without and with two millimeter thick aluminum casing, at a distance of $50 \mathrm{~mm}$ from the detonation points, are listed in Table II. Shock front arrival times obtained from Autodyn for the (HMX, TNT) PWG without and with boat tailing, without and with two millimeter thick aluminum casing at a distance of $67 \mathrm{~mm}$ from the detonation points are given in Table III. Matlab code was run to find the arrival time of shock front at $60 \mathrm{~mm}$ from the point of detonation. Additional $7 \mathrm{~mm}$ of HMX were added to the HMX part in order to ensure the proper detonation of the second low explosive which may deflagrate in some cases if the shock wave does not have enough energy [20]. In some cases the shock wave slowly dies out or attenuates and changes to a sound wave. Exploded views of HMX-Baratol and HMX-TNT PWGs are given in Figure 7.

TABLE II. SHOCK FRONT ARRIVAL TIME FOR (HMX-BARATOL) PWG

\begin{tabular}{|c|c|c|c|c|c|}
\hline \multirow{2}{*}{\multicolumn{2}{|c|}{ Position }} & \multicolumn{2}{|c|}{ Without Boat Tailing } & \multicolumn{2}{|c|}{ With Boat Tailing } \\
\hline & & Without Casing & With Casing & Without Casing & With Casing \\
\hline $\mathbf{X}$ & $\mathbf{Y}$ & \multicolumn{2}{|c|}{ Time $(\mu \mathrm{s})$} & \multicolumn{2}{|c|}{ Time $(\mu s)$} \\
\hline 50 & 0 & 7.579 & 7.569 & 7.576 & 7.535 \\
\hline 50 & 5 & 7.585 & 7.569 & 7.537 & 7.572 \\
\hline 50 & 10 & 7.615 & 7.569 & 7.563 & 7.572 \\
\hline 50 & 15 & 7.636 & 7.679 & 7.676 & 7.647 \\
\hline 50 & 20 & 7.734 & 7.735 & 7.753 & 7.787 \\
\hline 50 & 25 & 7.885 & 7.919 & 7.877 & 7.874 \\
\hline 50 & 30 & 7.992 & 8.012 & 8.049 & 8.002 \\
\hline 50 & 35 & 8.084 & 8.123 & 8.083 & 8.095 \\
\hline 50 & 40 & 8.029 & 8.067 & 8.026 & 8.077 \\
\hline 50 & 45 & 7.936 & 7.661 & 7.934 & 7.667 \\
\hline \multicolumn{2}{|c|}{$\begin{array}{c}\text { Average } \\
\text { Time }\end{array}$} & $\begin{array}{c}7.808 \\
\pm 0.505\end{array}$ & $\begin{array}{c}7.790 \\
\pm 0.554 \\
\end{array}$ & $\begin{array}{c}7.807 \\
\pm 0.546 \\
\end{array}$ & $\begin{array}{c}7.783 \\
\pm 0.560 \\
\end{array}$ \\
\hline
\end{tabular}

TABLE III. SHOCK FRONT ARRIVAL TIME FOR (HMX-TNT) PWG

\begin{tabular}{|c|c|c|c|c|c|}
\hline \multicolumn{2}{|c|}{ Position } & \multicolumn{2}{|c|}{$\begin{array}{c}\text { Time }(\mu s) \text { Without Boat } \\
\text { Tailing }\end{array}$} & \multicolumn{2}{|c|}{ Time( $\mu$ s) With Boat Tailing } \\
\hline $\mathbf{X}$ & $\mathbf{Y}$ & No Casing & $2 \mathrm{~mm}$ Casing & No Casing & $2 \mathrm{~mm}$ Casing \\
\hline 67 & 0 & 9.270 & 9.253 & 9.275 & 9.278 \\
\hline 67 & 5 & 9.234 & 9.237 & 9.235 & 9.234 \\
\hline 67 & 10 & 9.173 & 9.221 & 9.222 & 9.222 \\
\hline 67 & 15 & 9.206 & 9.205 & 9.208 & 9.209 \\
\hline 67 & 20 & 9.173 & 9.205 & 9.205 & 9.209 \\
\hline 67 & 25 & 9.199 & 9.202 & 9.202 & 9.203 \\
\hline 67 & 30 & 9.199 & 9.202 & 9.202 & 9.209 \\
\hline 67 & 35 & 9.196 & 9.197 & 9.195 & 9.198 \\
\hline 67 & 40 & 9.141 & 9.119 & 9.191 & 9.110 \\
\hline 67 & 45 & 9.199 & 9.202 & 9.198 & 9.198 \\
\hline \multicolumn{2}{|c|}{$\begin{array}{l}\text { Average } \\
\text { Time }\end{array}$} & $\begin{array}{c}9.199 \pm \\
0.129 \\
\end{array}$ & $\begin{array}{c}9.204 \pm \\
0.134 \\
\end{array}$ & $\begin{array}{c}9.213 \pm \\
0.084\end{array}$ & $\begin{array}{c}9.207 \pm \\
0.168\end{array}$ \\
\hline
\end{tabular}

\section{RESULTS AND DISCUSSION}

Only six points were taken from the entire explosive profile for the modeling of the PWG profile in Ansys Autodyn. Instead of these huge simplifications, flat detonation wave fronts were obtained for both PWGs. Figures 3 and 4 show that decreasing step size increased the number of points for the profile. In other words, accuracy increased at the cost of computational time. These figures also depict that by selecting two explosives having a large difference in VOD, a PWG with smaller height can be designed. Current flatness given in Tables II and III was achieved by drawing two arcs in Autodyn to model and simulate the PWG profile. Flatness can be further improved by fitting multiple arcs to the points generated by Matlab. Table IV depicts that boat-tailing of the PWG reduced the mass of PWG by $41.39 \%$ and $26.68 \%$ respectively for HMX-Baratol and HMX-TNT PWG. This huge mass reduction decreases the cost of PWG without any sacrifice in its simultaneity. The reduction in explosive reduces the blast effect and the volume of the gases evolved during detonation which degrades the environment. Replacing the Baratol with TNT increased the 
PWG length. But the simultaneity of the later is better than the previous as can be seen in Figures 5 and 6. In areas where smaller size is required, it is better to use two explosives which have large difference in their detonation velocity like HMX and Baratol.

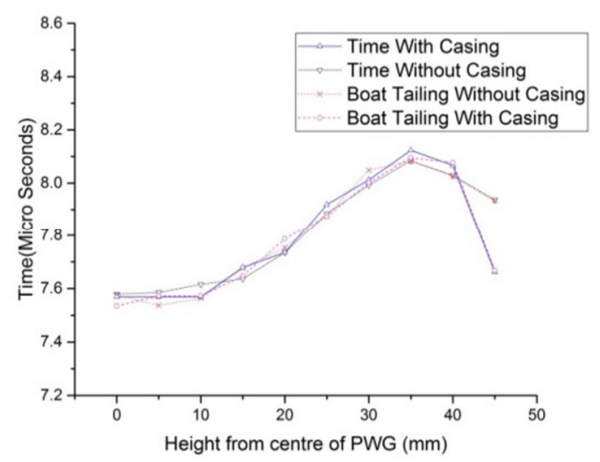

Fig. 5. Effect of boat tailing and casing on simultaneity of HMX-Baratol PWG

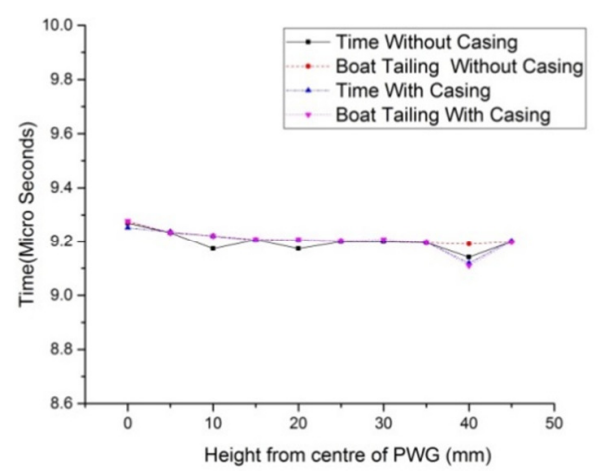

Fig. 6. Effect of boat tailing and casing on simultaneity of HMX-TNT PWG

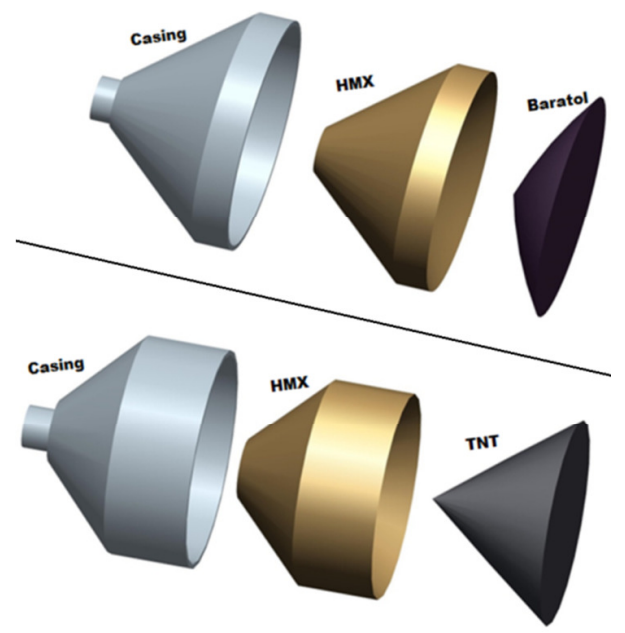

Fig. 7. Exploded view of HMX-Baratol and HMX-TNT PWG

Inclusion of casing does affect the timings as can be seen in Figures 5 and 6 but this effect is very small and can be considered negligible. In order to make a PWG of $90 \mathrm{~mm}$ diameter, it is better to model a PWG of $100 \mathrm{~mm}$ diameter and then reduce the diameter to $90 \mathrm{~mm}$ by turning. This will reduce the edge effects. These effects decrease the PWG performance by the late arrival of the shock front near the outer periphery. It happens because there is not enough high explosive in the periphery to properly detonate the second less sensitive explosive having lesser VOD. This crude Matlab code which only relies on the detonation velocity of explosives gives a good approximation for the profile of PWG.

TABLE IV. EFFECT OF BOAT TAILING ON THE MASS OF PWG

\begin{tabular}{|c|c|c|c|c|c|}
\hline PWG & Variation & $\begin{array}{c}\text { HMX } \\
\text { (gm) }\end{array}$ & $\begin{array}{c}\text { Baratol/TNT } \\
(\mathrm{gm})\end{array}$ & $\begin{array}{l}\text { Total } \\
\text { mass } \\
(\mathrm{gm})\end{array}$ & $\begin{array}{c}\% \\
\text { Decrease }\end{array}$ \\
\hline \multirow{2}{*}{$\begin{array}{l}\text { HMX, } \\
\text { Baratol }\end{array}$} & $\begin{array}{c}\text { Without } \\
\text { Boat Tailing }\end{array}$ & 522.79 & 147.21 Baratol & 670 & \multirow{2}{*}{41.39} \\
\hline & $\begin{array}{c}\text { With Boat } \\
\text { Tailing }\end{array}$ & 245.46 & 147.21 Baratol & 392.67 & \\
\hline \multirow{2}{*}{$\begin{array}{l}\text { HMX, } \\
\text { TNT }\end{array}$} & $\begin{array}{c}\text { Without } \\
\text { Boat Tailing }\end{array}$ & 535.97 & 204.77 TNT & 740.74 & \multirow{2}{*}{26.68} \\
\hline & $\begin{array}{c}\text { With Boat } \\
\text { Tailing } \\
\end{array}$ & 338.30 & 204.77 TNT & 543.07 & \\
\hline
\end{tabular}

\section{CONCLUSION}

Matlab code was successfully written to obtain the PWG profile for any two explosives having dissimilar VOD and the results were compared with the simulation runs on Ansys Autodyn. Results were quite in agreement, even with the inclusion of aluminum casing and boat tailing. Boat tailing reduced the mass of explosive by $41.39 \%$ and $26.68 \%$ without the cost of losing simultaneity. Boat tailing reduced the amount of exhaust gases to the atmosphere by reducing the amount of explosives in the PWG. To check the effect of step size in Matlab, four successive decreasing step sizes were employed. This increased the computational time and the number of data points or accuracy. With the developed Matlab code any two explosives with dissimilar VOD can be selected to design a PWG. It is better to have two explosives which have a wide gap in their VOD. Replacing Baratol with TNT not only increased the length of PWG as shown in Figure 7 but also improved its simultaneity as given in Tables II and III. The developed code reduces the cost of PWG by decreasing the number of tests required to finalize the PWG.

\section{REFERENCES}

[1] A. Mitchell, W. Nellis, "Diagnostic system of the Lawrence Livermore National Laboratory two-stage light-gas gun", Review of Scientific Instruments, Vol. 52, No. 3, pp. 347-359, 1981

[2] L. C. Chhabildas, M. D. Knudson, "Techniques to launch projectile plates to very high velocities", in: High-Pressure Shock Compression of Solids VIII, Springer, pp. 143-199, 2005

[3] L. C. Chhabildas, Hypervelocity Launch Capabilities to Over $10 \mathrm{~km} / \mathrm{s}$, Sandia National Labs., Albuquerque, NM, USA, 1991

[4] J. E. Osher, H. H. Chau, G. R. Gathers, R. S. Lee, R. C. Weingart, "Application of a 100-kV electric gun for hypervelocity impact studies", International Journal of Impact Engineering, Vol. 5, No. 1-4, pp. 501507,1987

[5] A. B. Wenzel, "A review of explosive accelerators for hypervelocity impact", International Journal of Impact Engineering, Vol. 5, No. 1-4, pp. 681-692, 1987

[6] W. Xiong, X. Zang, Z. Guan, Y. He, L. Qiao, L. Guo, "Study of simple plane wave generator with an air-metal barrier", Defence Technology, Vol. 10, No. 2, pp. 190-197, 2014 
[7] B. Olinger, Solid Explosive Plane-Wave Lenses Pressed-to-Shape with Dies, Los Alamos National Laboratory, Los Alamos, NM, USA, 2007

[8] K. Jin, X. M. Zhou, X. H. Liu, F. Xi, "Design of Plane-wave Lens Utilizing Nitromethane and Lead [J]", Energetic Materials, Vol. 2, 2005

[9] S. N. Li, X. Zhou, S. Yuan, P. Song, W. Wang, S. H. Yei, "Manufacture of Low Equivalent Liquid Explosive Lens without Lead [J]", Chinese Journal of Energetic Materials, Vol. 3, 2006

[10] J. Crutchmer, Slow PBX and Plane-Wave Lens Development, Mason and Hanger-Silas Mason, Amarillo, USA, 1973

[11] R. H. Christian, F. L. Yarger, "Equation of state of gases by shock wave measurements. I. Experimental method and the Hugoniot of argon", The Journal of Chemical Physics, Vol. 23, No. 11, pp. 2042-2044, 1955

[12] H. Kato, K. Murata, S. Itoh, Y. Kato, "Application of overdriven detonation in high density explosive to shaped charge", 23rd International Symposium on Ballistics, Tarragona, Spain, April 16-20, 2007

[13] A. Merendino, J. M. Regan, S. Kronman, A Method of Obtaining a Massive Hypervelocity Pellet From a Shaped Charge Jet, Ballistic Research Laboratories, USA, 1963

[14] M. A. Meyers, U. R. Andrade, A. H. Chokshi, "The effect of grain size on the high-strain, high-strain-rate behavior of copper", Metallurgical and Materials Transactions A, Vol. 26, No. 11, pp. 2881-2893, 1995

[15] K. Naeem, A. Hussain, "Numerical and experimental study of wave shaper effects on detonation wave front", Defence Technology, Vol. 14, No. 1, pp. 45-50, 2017

[16] J. Petit, V. Jeanclaude, C. Fressengeas, "Breakup of copper shapedcharge jets: Experiment, numerical simulations, and analytical modeling", Journal of Applied Physics, Vol. 98, No. 12, pp. 123521-1123521-10, 2005

[17] M. Ahmed, A. Q. Malik, S. A. Rofi, Z. X. Huang, "Penetration Evaluation of Explosively Formed Projectiles Through Air and Water Using Insensitive Munition: Simulative and Experimental Studies", Engineering, Technology \& Applied Science Research, Vol. 6, No. 1, pp. 913-916, 2016

[18] E. Lee, M. Finger, W. Collins, JWL Equation of State Coefficients for High Explosives, Lawrence Livermore National Lab., 1973

[19] C. M. Tarver, J. W. Kury, R. D. Breithaupt, "Detonation waves in triaminotrinitrobenzene", Journal of Applied Physics, Vol. 82, No. 8, pp. 3771-3782, 1997

[20] B. Narin, Y. Ozyoruk, A. Ulas, "Two dimensional numerical prediction of deflagration-to-detonation transition in porous energetic materials", Journal of Hazardous Materials, Vol. 273, pp. 44-52, 2014 